International Journal of Current Advanced Research

ISSN: O: 2319-6475, ISSN: P: 2319 - 6505, Impact Factor: SJIF: 5.995

Available Online at www.journalijcar.org

Volume 6; Issue 4; April 2017; Page No. 3124-3126

DOI: http://dx.doi.org/10.24327/ijcar.2017.3126.0200

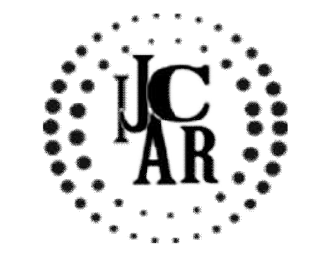

Research Article

\title{
EFFECT OF AEROBICS EXERCISE AND YOGA ON BLOOD PRESSURE IN HYPERTENSIVES
}

\section{Sarvesh Kumar J and Preetha S}

Saveetha Dental College and Hospitals, 162, P.H Road, Chennai, Tamilnadu 600077

\begin{tabular}{l}
\hline A R T I C L E I N F O \\
\hline Article History: \\
Received $12^{\text {th }}$ January, 2017 \\
Received in revised form $19^{\text {th }}$ February, 2017 \\
Accepted $28^{\text {th }}$ March, 2017 \\
Published online $28^{\text {th }}$ April, 2017
\end{tabular}

\section{Key words:}

Hypertensive patients, Blood pressure, yoga, aerobics exercise.

\begin{abstract}
A B S T R A C T
Aim: To verify how blood pressure is altered by aerobics and yoga among hypertensive patients.

Background: High blood pressure is a major risk factor for stroke, coronary heart disease, end stage renal disease and congestive heart failure. Hypertension is generally treated by antihypertensive drugs which shows significant reduction in blood pressure. Any medication can cause side effects and high blood pressure medications are no exception, alternatively exercises and dietary habits are a good cure for hypertension

Methods: For the study 30 volunteers who were hypertensive were included and divided into 2 groups, namely participants doing aerobics exercise and yoga, and their maximum (systole) and minimum (diastole) blood pressures were measured using an automatic blood pressure monitor. The participants were made to undergo a 1 month of regular aerobics exercise and yoga practice and the variation in blood pressure was evaluated using spss software

Results: On analyzing the results it was observed that regular aerobics exercise and yoga tend to reduce the blood pressure among both the groups but the reduction was more among participants doing yoga

Reason: Exercises for the treatment and prevention of hypertension has increased, one of the most common exercise is aerobics. So this study is done to know the effect of aerobics and yoga on blood pressure in hypertensive patients
\end{abstract}

Copyright $₫ 2017$ Sarvesh Kumar J and Preetha S. This is an open access article distributed under the Creative Commons Attribution License, which permits unrestricted use, distribution, and reproduction in any medium, provided the original work is properly cited.

\section{INTRODUCTION}

Blood pressure (BP) is the pressure exerted by circulating blood upon the walls of blood vessels. Blood pressure is expressed by two measurements, the systolic pressure and diastolic pressure, which are the maximum and minimum pressures, respectively. The Normal blood pressure at the state of rest is within the range of 100-140 millimeters mercury $(\mathrm{mmHg})$ systolic and $60-90 \mathrm{mmHg}$ diastolic. ${ }^{[1]}$ High blood pressure is present if the resting blood pressure is persistently at or above $140 / 90 \mathrm{mmHg}$ for most adults.

\begin{tabular}{ccc}
\hline & Systole BP & Diastole BP \\
\hline Normal & $<120$ & $<80$ \\
Prehypertension & $120-139$ & $80-89$ \\
Stage 1 hypertension & $140-159$ & $90-99$ \\
Stage 2 hypertension & $>160$ & $>100$ \\
\hline
\end{tabular}

The amount of blood pumped by the heart and the size and condition of the arteries determines your blood pressure. ${ }^{[2]}$ However, many other factors can affect blood pressure including the condition of your kidneys and levels of various hormones in the body. High blood pressure is a common condition in which the long-term force of the blood against

*Corresponding author: Sarvesh Kumar J

Saveetha Dental College and Hospitals, 162, P.H Road,

Chennai, Tamilnadu 600077 your artery walls is high enough that it may eventually cause health problems, such as heart disease. ${ }^{[3]}$ Blood pressure is determined both by the amount of blood your heart pumps and the amount of resistance to blood flow in your arteries. The more blood your heart pumps and the narrower your arteries, the higher your blood pressure. ${ }^{[4]}$ If you have high blood pressure, the force exerted on your arteries is too high. It's so high that it creates microscopic tears in the artery walls that then turn into scar tissue. Hypertension, also known as high blood pressure, is a long term medical condition in which the blood pressure is persistently elevated in the arteries. ${ }^{[5]}$ Hypertension stresses your body's blood vessels, causing them to clog or weaken. Hypertension can lead to atherosclerosis and narrowing of the blood vessels making them more likely to block from blood clots or bits of fatty material breaking off from the lining of the blood vessel wall. High blood pressure usually does not cause symptoms. Long term high blood pressure is a major risk factor for coronary artery disease, stroke, vision loss, chronic kidney disease, heart failure and peripheral vascular disease, Hypertension and prehypertension have been increasing among children and adolescents since the 1990s. [6, 7$]$ Hypertension affects approximately 50 million individuals in the United States and approximately 1 billion worldwide. ${ }^{[8]}$ 
Any medication can cause side effects and high blood pressure medications are no exception ${ }^{[9]}$, alternatively exercises are a good cure for hypertension. Physical activity and fitness have often been found to be inversely proportional to the incidence and severity of hypertension. Making exercise a habit can help lower your blood pressure. It also gives you more energy and is a great way to ease stress and feel better. Regular exercise is strongly recommended to reduce hypertension. ${ }^{[10]}$ Aerobic exercise can help lower your blood pressure and make your heart stronger. ${ }^{[1]}$ Hypertensives are generally encouraged to "employ in aerobic exercise on a regular basis, such as walking, running, jogging or swimming for 30 to 45 minutes daily." In people with normal blood pressure (normotensives), regular exercise reduces systolic blood pressure by 3 to $5 \mathrm{~mm} \mathrm{Hg}$ and diastolic blood pressure by 2 to $3 \mathrm{~mm} \mathrm{Hg}$. In hypertensives, this effect is even more pronounced. Although heredity plays a role in blood pressure variability, diet and lifestyle exert considerable influence in blood pressure regulation. ${ }^{[8]}$ Earlier studies also suggest that non vegetarian diet leads to high blood pressure. ${ }^{[12]}$ Blood pr Therefore this study was done to know how blood pressure is altered by aerobics exercise and yoga among hypertensive patients.

\section{METHODS}

The study was conducted among 30 hypertensive patients in an aerobics gym and yoga centre, the participants were aged between 30-60 years. The inclusive factors were the patients should not be under any medications for hypertension, the participants must be undertaking a regular diet and had no adverse oral habits like smoking and drinking alcohol and must do regular exercise. The participants not falling under inclusive factors were excluded. The participants were explained about the study and the volunteers were included. The participants were split into two groups, first group with people doing aerobics exercise which included 15 participants and another group with 15 participants doing yoga making up to a total of 30 patients. The blood pressure of the participants were estimated twice, first time during their first visit to the center before starting their practice and second time after 1 month of practice. During both visit the blood pressure of the patients were checked after a five minutes of rest before beginning of the workout using a automatic blood pressure monitor, the systolic and diastolic pressure were noted in $\mathrm{mm}$ $\mathrm{Hg}$ separately and the values were entered and evaluated using spss software and the results were analyzed.

\section{RESULT}

On analysis of data it is observed that after aerobics exercise the mean reduction in systolic and diastolic pressure was 2.93 $\mathrm{mmHg}$ and $2.87 \mathrm{mmHg}$ respectively and the mean reduction in systolic and diastolic pressure in people performing yoga was $8.0 \mathrm{mmHg}$ and $10.0 \mathrm{mmHg}$ respectively and the " $p$ value" of the study was not significant

Table 1 Hypertensive Patients Doing Aerobics Aerobics

\begin{tabular}{ccccc}
\hline Groups & $\begin{array}{c}\text { Systolic } \\
\text { Pressure } \\
\text { Before } \\
\text { Aerobics } \\
\text { Exercise }\end{array}$ & $\begin{array}{c}\text { Systolic } \\
\text { Pressure After } \\
\text { Aerobics } \\
\text { Exercise }\end{array}$ & $\begin{array}{c}\text { Diastolic } \\
\text { Pressure } \\
\text { Before } \\
\text { Aerobics } \\
\text { Exercise }\end{array}$ & $\begin{array}{c}\text { Diastolic } \\
\text { Pressure After } \\
\text { Aerobics } \\
\text { Exercise }\end{array}$ \\
\hline $\begin{array}{c}\text { Mean } \\
\text { Standard } \\
\text { deviation }\end{array}$ & 149.8667 & 146.9333 & 94.6000 & 91.7333 \\
\hline
\end{tabular}

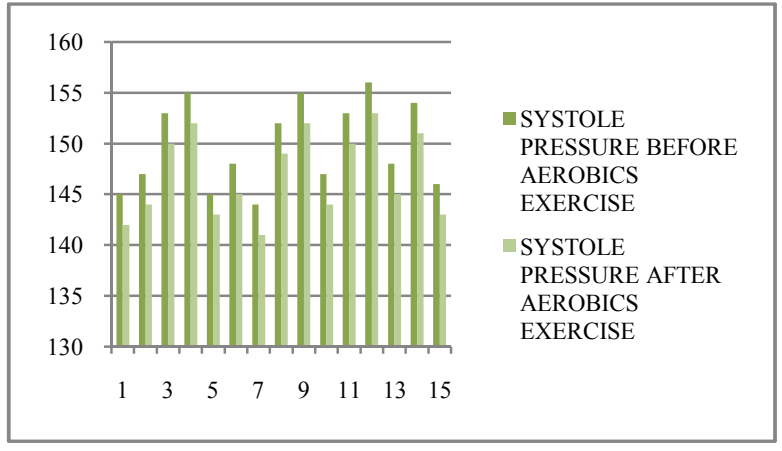

Figure 1 Variation In Systole Pressure Among Participants Doing Aerobics Exercise

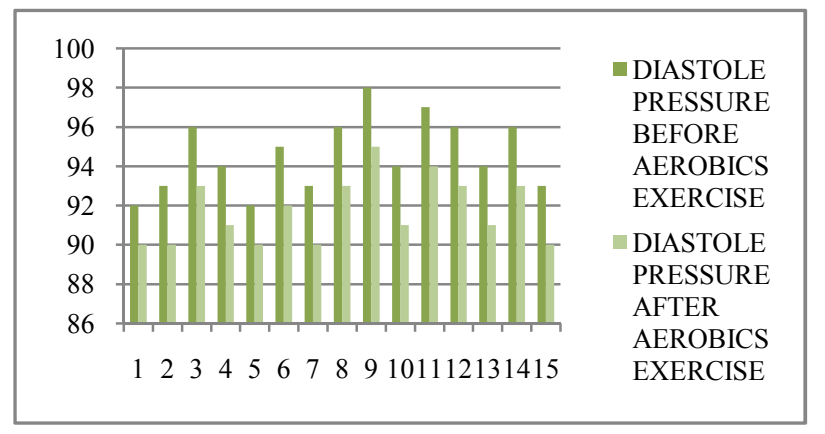

Figure 2 Variations in Dyastolic Pressure among Participants Doing Aerobics Exercise

Table 2 among Hypertensive Patients Doing Yoga

\begin{tabular}{|c|c|c|c|c|}
\hline \multirow{4}{*}{ Groups } & Systolic & Systolic & Diastolic & Diastolic \\
\hline & Pressure Before & Pressure After & Pressure Before & Pressure After \\
\hline & Aerobics & Aerobics & Aerobics & Aerobics \\
\hline & Exercise & Exercise & Exercise & Exercise \\
\hline \multirow{2}{*}{$\begin{array}{c}\text { Mean } \\
\text { Standard } \\
\text { deviation } \\
\end{array}$} & 120.2000 & 109.4667 & 86.1333 & 68.6000 \\
\hline & 13.61302 & 13.81442 & 5.55321 & 16.08371 \\
\hline
\end{tabular}

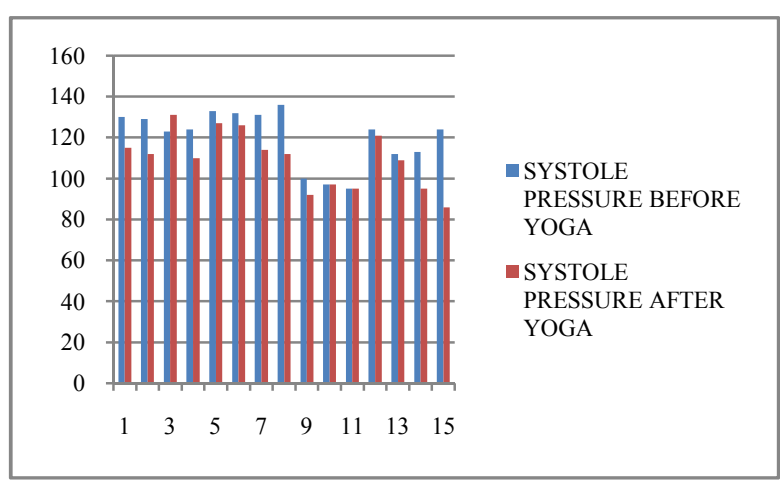

Figure 3 Variations in Systolic Pressure among Participants Doing Yoga

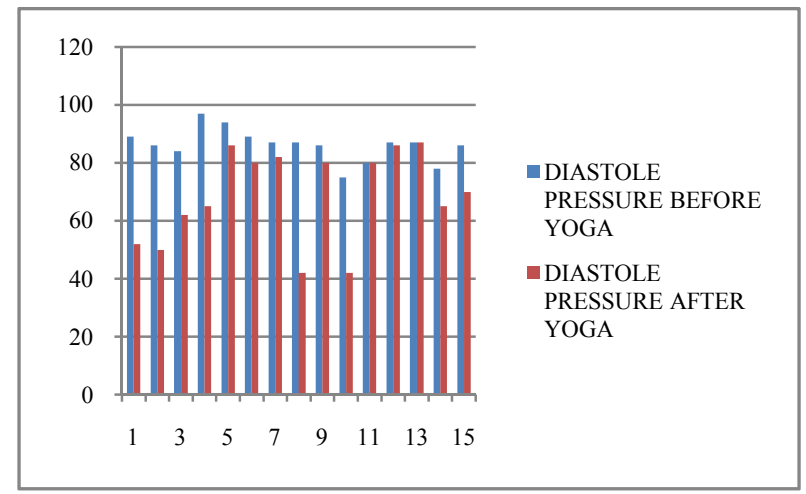

Figure 4 Variations Diastolic Pressure among Participants Doing Yoga 


\section{DISCUSSION}

Hypertension is a disease which is nowadays most commonly seen among children and adolescents and has been found that regular exercise tends to reduce the levels of high blood pressure in a very effective way among which the effects of aerobics exercise on reducing high blood pressure in hypertensive patients had been more convincing that regular aerobics exercise reduces the blood pressure by $>1.5 \mathrm{mmHg}$. High blood pressure is a major risk factor for stroke, coronary heart disease, congestive heart failure, and end stage renal disease. ${ }^{[13-15]}$ Cornelissen et.al ${ }^{[16]}$ in their study among 5223 participants after high endurance training the mean reduction in systolic blood pressure was found to be $3.5 \mathrm{mmHg}$ and the mean reduction in diastolic blood pressure was found to be $2.5 \mathrm{mmHg}$. Murugesan et.al ${ }^{[17]}$ in their study among 33 participants after 11 weeks of yoga practice was found to show a makeable reduction in systolic blood pressure. In the present study it is observes that regular aerobics exercise reduces the blood pressure (both systolic and diastolic pressures) in hypertensive patients. From figure $1 \& 2$ it is inferred that among participants doing aerobics exercise the systolic and diastolic pressures decrease after regular exercise, from figure $3 \& 4$ it is inferred that also among participants doing yoga the systolic and diastolic pressures decrease after regular practice. Therefore though there is a reduction systolic pressure and diastolic pressures among both the study groups, among participants doing yoga the reduction in blood pressure was found to be more than people doing aerobics exercise.

\section{CONCLUSION}

Hypertension is one of the most common diseases found across the world in all groups of age. The present study helped us to identify that aerobics exercise and yoga practice helps to reduce blood pressure in hypertensive patients, it is more recommended than medication because aerobics exercise and yoga will not produce any side effects like medicines and further studies must be done in this field to help hypertensive patients to reduce blood pressure in a more effective manner without any side effects.

\section{References}

1. Master, Arthur M. "The Normal Blood Pressure Range And Its Clinical Implications." JAMA Journal of the American Medical Association 143.17 (1950): 1464.

2. Parati, Gianfranco, Guido Pomidossi, Fabio Albini, Daniele Malaspina, and Giuseppe Mancia. "Relationship of 24-Hour Blood Pressure Mean and Variability to Severity of Target-Organ Damage in Hypertension." Journal of Hypertension 5.1 (1987): 93-98.

3. Wootton, David M., and David N. Ku. "Fluid Mechanics of Vascular Systems, Diseases, and Thrombosis." Annual Review of Biomedical Engineering Annu. Rev. Biomed. Eng. 1.1 (1999): 299-329.

4. Benetos, A., S. Laurent, A. P. Hoeks, P. H. Boutouyrie, and M. E. Safar. "Arterial Alterations with Aging and High Blood Pressure. A Noninvasive Study of Carotid and Femoral Arteries." Arteriosclerosis, Thrombosis, and Vascular Biology 13.1 (1993): 90-97.
5. Perloff, D., C. Grim, J. Flack, E. D. Frohlich, M. Hill, M. Mcdonald, and B. Z. Morgenstern. "Human Blood Pressure Determination by Sphygmomanometry." Circulation 88.5 (1993): 2460-470.

6. Ostchega Y, Carroll M, Prineas RJ, McDowell MA, Louis T, Tilert T. Trends of elevated blood pressure among children and adolescents: data from the National Health and Nutrition Examination Survey 1988-2006. Am J Hypertens 2009; 22:59-67.

7. Din-Dzietham R, Liu Y, Bielo M, Shamsa F. High blood pressure trends in children and adolescents in national surveys, 1963-2002. Circulation 2007; 116:1488-96.

8. Berkow, Susan E., and Neal D. Barnard. "Blood Pressure Regulation and Vegetarian Diets." Nutrition Reviews 63.1 (2005): 1-8.

9. Hansson, Lennart, Alberto Zanchetti, S. George Carruthers, Björn Dahlöf, Dag Elmfeldt, Stevo Julius, Joël Ménard, Karl Heinz Rahn, Hans Wedel, and Sten Westerling. "Effects of Intensive Blood-pressure Lowering and Low-dose Aspirin in Patients with Hypertension: Principal Results of the Hypertension Optimal Treatment (HOT) Randomised Trial." The Lancet 351.9118 (1998): 1755-762. Web.

10. Engström, Gunnar, Bo Hedblad, and Lars Janzon. "Hypertensive Men Who Exercise Regularly Have Lower Rate of Cardiovascular Mortality." Journal of Hypertension 17.6 (1999): 737-42.

11. Fagard, Rh. "Exercise Is Good For Your Blood Pressure: Effects Of Endurance Training And Resistance Training." Clin Exp Pharmacol Physiol Clinical and Experimental Pharmacology and Physiology 33.9 (2006): 853-56. Web.

12. Appel, Lawrence J., Thomas J. Moore, Eva Obarzanek, William M. Vollmer, Laura P. Svetkey, Frank M. Sacks, George A. Bray, Thomas M. Vogt, Jeffrey A. Cutler, Marlene M. Windhauser, Pao-Hwa Lin, Njeri Karanja, Denise Simons-Morton, Marjorie Mccullough, Janis Swain, Priscilla Steele, Marguerite A. Evans, Edgar R. Miller, and David W. Harsha. "A Clinical Trial of the Effects of Dietary Patterns on Blood Pressure." New England Journal of Medicine N Engl J Med 336.16 (1997): 1117-124.

13. 2000 heart and Stroke Statistical Update. American Heart Association. Dallas, TX: American Heart Assoc; 1999.

14. He J, Whelton PK. Elevated systolic blood pressure and risk of cardiovascular and renal disease: overview of evidence from observational epidemiologic studies and randomized controlled trials. Am Heart J. 1999; 138:211-9. [PMID:10467215]

15. Whelton PK, He J. Blood pressure reduction. In: Hennekens CH, Buring JE, Manson JE, Ridker PM, eds. Clinical Trials in Cardiovascular Disease. Philadelphia: WB Saunders; 1999.

16. Cornelissen, V. A., and N. A. Smart. "Exercise Training for Blood Pressure: A Systematic Review and Meta-analysis." Journal of the American Heart Association 2.1 (2013). Web.

17. R. Murugesan, N. Govindarajulu and T. K. Bera. "Effect of Selected Yogic Practices On The Management of Hypertension." Indian J Physiol Pharmacol 2000; 44 (2): 207-210 